\title{
Modeling and Analysis of Static and Dynamic Characteristics of Nonlinear Seat Suspension for Off-Road Vehicles
}

\author{
Zhenhua Yan, ${ }^{1}$ Bing Zhu, ${ }^{2}$ Xuefei Li, ${ }^{1}$ and Guoqiang Wang ${ }^{1}$ \\ ${ }^{1}$ School of Mechanical Science and Engineering, Jilin University, Changchun 130022, China \\ ${ }^{2}$ State Key Laboratory of Automotive Simulation and Control, Jilin University, Changchun 130022, China \\ Correspondence should be addressed to Bing Zhu; zhubing@jlu.edu.cn
}

Received 7 May 2015; Revised 17 July 2015; Accepted 11 August 2015

Academic Editor: Miguel Neves

Copyright (c) 2015 Zhenhua Yan et al. This is an open access article distributed under the Creative Commons Attribution License, which permits unrestricted use, distribution, and reproduction in any medium, provided the original work is properly cited.

\begin{abstract}
Low-frequency vibrations $(0.5-5 \mathrm{~Hz})$ that harm drivers occur in off-road vehicles. Thus, researchers have focused on finding methods to effectively isolate or control low-frequency vibrations. A novel nonlinear seat suspension structure for off-road vehicles is designed, whose static characteristics and seat-human system dynamic response are modeled and analyzed, and experiments are conducted to verify the theoretical solutions. Results show that the stiffness of this nonlinear seat suspension could achieve real zero stiffness through well-matched parameters, and precompression of the main spring could change the nonlinear seat suspension performance when a driver's weight changes. The displacement transmissibility curve corresponds with the static characteristic curve of nonlinear suspension, where the middle part of the static characteristic curve is gentler and the resonance frequency of the displacement transmissibility curve and the isolation minimum frequency are lower. Damping should correspond with static characteristics, in which the corresponding suspension damping value should be smaller given a flatter static characteristic curve to prevent vibration isolation performance reduction.
\end{abstract}

\section{Introduction}

Off-road vehicles have been used widely in recent years. Such vehicles are usually driven and work on gravel or rough surfaces, which cause severe vibrations. These vibrations are usually at low frequency, ranging below $5 \mathrm{~Hz}$. Vibrations at low excitation frequencies $(0.5-5 \mathrm{~Hz})$ are the main risk factors for lumbago or backache, which seriously affects mental and physical health and reduces the work efficiency of drivers and passengers [1-5]. Hence, such vibrations require isolation, but linear isolation theory is inapplicable because this theory is only useful when the ratio between the excitation and natural frequencies of the isolation system is more than $\sqrt{2}$. Thus, the isolation system should have a lower natural frequency if the excitation frequency is low. The natural frequency formula is $\sqrt{k / m}$, where the body mass $m$ of the driver is constant, while stiffness $k$ should be small. A small system natural frequency may be obtained, but the static deformation of the system is large [6-8].

Researchers have introduced several methods, such as the active, semiactive, and nonlinear seat suspensions, to isolate low-frequency vibrations from off-road vehicles. Maciejewski studied the active vibration control strategy based on the reverse dynamics of a force actuator and a primary controller. Primary controller settings were calculated via multicriteria optimization, which subsequently defined vibroisolation characteristics of active suspension [9]. Sun et al. investigated the problem of $H_{\infty}$ control for active seat suspension systems via dynamic output feedback control [10]. Stein et al. studied the seat vertical suspension system of a locomotive driver using an adjustable damper [11]. Choi et al. studied a semiactive seat suspension using an electrorheological fluid damper [12]. Bouazara et al. studied the safety and comfort of a 3D vehicle model with optimal nonlinear active seat suspension and found that the comfort performance of a suspension seat with semiactive and active dampers could be considerably enhanced by $20-30 \%$ [13].

Active and semiactive seat suspensions possess complicated structures and require outside energy. By contrast, nonlinear seat suspensions do not require outside energy and exhibit simple structures. Le and Ahn designed and fabricated a vibration isolation model to improve vibration 

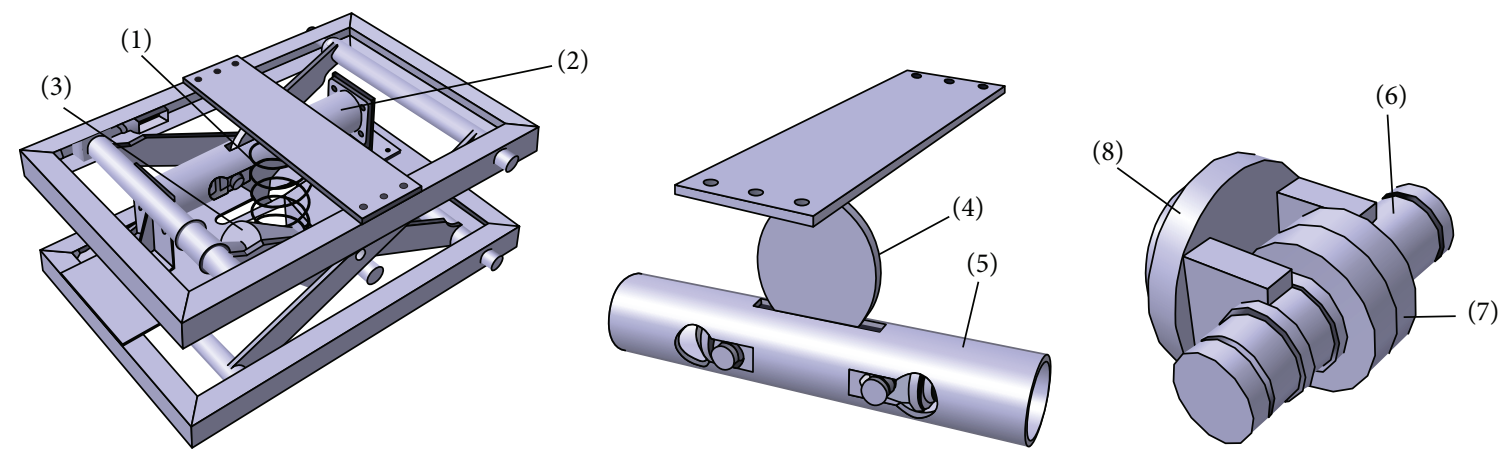

FIgURE 1: 3D model of nonlinear seat suspension.

isolation effectiveness of seats under low excitation frequencies [14]. Lee and Goverdovskiy studied nonlinear seat suspension mechanisms and researched synthesis-type function-generating mechanisms for seat suspensions [15]. Park invented a vibration isolation system with a unique low vibration frequency [16]. Jutte and Kota described a comprehensive approach as compliant elements development of a prescribed nonlinear stiffness; a nonlinear spring can be used for seat suspensions [17].

The nonlinear seat suspension technology originates from the nonlinear isolator technology. Carrella et al. studied a simple system that comprised a vertical spring acting in parallel with two oblique springs and obtained the static characteristics of a passive vibration isolator with quasi-zerostiffness characteristic [18]. Ahn studied the performance limit of a passive vertical isolator using a negative stiffness mechanism and presented isolator design guidelines based on the performance limit of the isolator [19]. Kovacic et al. studied a vibration isolator that comprised a vertical linear spring and two nonlinear prestressed oblique springs, which both exhibited geometrical and physical nonlinearities [20]. Carrella et al. studied the force and displacement transmissibility of a nonlinear isolator with high-static-lowdynamic stiffness [21].

Some researchers have also studied the vibration isolation system, which comprises a nonlinear isolator and an active control system. Danh and Ahn studied and proposed an active pneumatic vibration isolation system using negative stiffness structures for a vehicle seat under low excitation frequencies [22].

Many mechanisms in existing studies could be used for seat nonlinear suspension; the mechanism with vertical and two horizontal springs or with an instability shell is widely researched. Furthermore, suspension is commonly investigated during characteristics analysis, and the human body is simplified as a single mass. A driver and seat suspension actually exhibits strong coupling, and human driver's characteristics should be involved in seat suspension development. However, the seat-human system integrated dynamic model receives insufficient attention.

A novel nonlinear seat suspension structure for off-road vehicles is designed in this study to broaden the seat nonlinear suspension forms and explore the best performance; this structure is simple and can achieve an ideal zerostiffness isolation performance. Static characteristics are then modelled and an experiment is conducted. A classic fourdegree-of-freedom (4DOF) human model is coupled with a seat model that possesses nonlinear suspension, and seathuman system dynamic characteristics are finally researched. The test results show that the stiffness of this nonlinear seat suspension could achieve real zero stiffness using wellmatched parameters, and precompressing the main spring could change the nonlinear seat suspension performance when a driver's weight changes.

\section{Static Characteristic Modelling and Experimental Verification}

2.1. System Description. A novel nonlinear seat suspension is presented in this paper, whose $3 \mathrm{D}$ model created using the CATIA software is shown in Figure 1. This seat suspension comprises a shear-type frame, a main spring (1), a negative stiffness mechanism (2), and a damper (3). The negative stiffness mechanism comprises a curved edge component (4), a tube (5), a pair of axles (6), a pair of bearings (7), a pair of location pieces (8), and two horizontal springs at both ends of the tube.

When a driver sits on a seat with nonlinear suspension, the upper frame with the curved edge component (4) descends, the bearings (7) roll on the curved edge component (4), and the horizontal springs are compressed. The system finally becomes balanced, and the bearings make contact with the high points of the curved edge component (4). When off-roading, vibration is transmitted down to the driver-seatsuspension frame. The curved edge component ascends and descends with the center as the balance point, and vibration can then be isolated.

2.2. Modelling. The aforementioned nonlinear seat suspension can be abstracted into a mechanical model, as shown in Figures 2(a) and 2(b). Here, the stiffness of main spring 1 is $k_{1}$; the equivalent stiffness of the horizontal springs 4 is $k_{2}$; frame 2 is the upper frame of the shear-type suspension; roller 3 is the bearing; structure 5 is the curved edge component; and force $F$ is the driver's gravity. When force $F$ increases from 


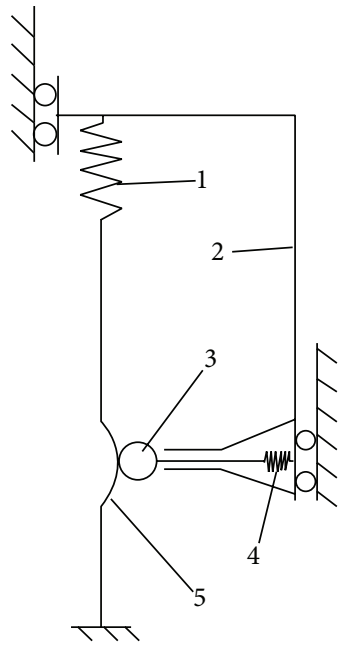

(a)

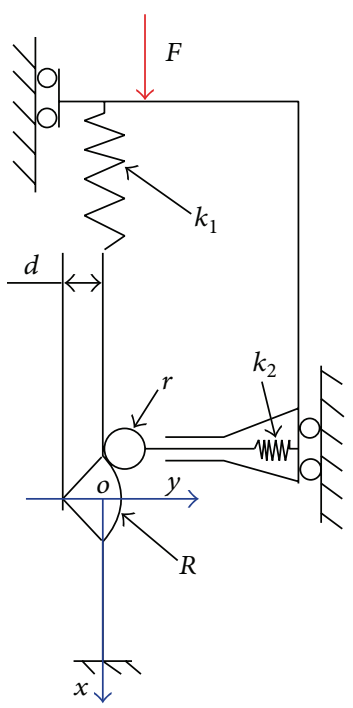

(b)

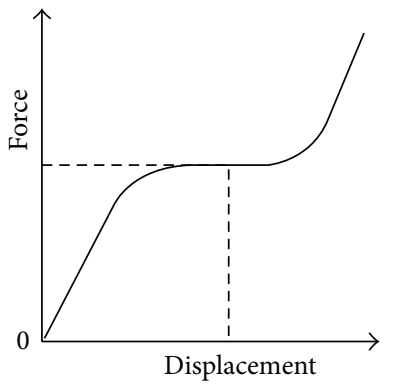

(c)

FIGURE 2: Mechanical model.

zero to the driver's gravity, frame 2 descends and roller 3 rolls on the curved edge of component 5 . The static mechanical characteristics of the whole system are similar to the graph in Figure 2(c), where the stiffness is minimal at the middle; the characteristics can also be called high-static stiffness and lowdynamic stiffness. The precompression of main spring 1 is assumed to be $u_{1}$, while the precompression of the horizontal spring is $u_{2}$; the curved edge radius of component 5 is $R$; and the radius of roller 3 is $r$. The precompression of the main spring 1 is assumed to be $u_{1}$, while the precompression of the horizontal spring is $u_{2}$, as shown in Figure 2(b).

The above parameters should meet the basic geometric constraints to achieve suspension:

$$
\begin{aligned}
& r>0, \\
& d>0, \\
& R>d, \\
& u_{1} \geq 0, \\
& u_{2} \geq 0 .
\end{aligned}
$$

When the system is in the state shown in Figure 2(b), the coordinates of the center of roller 3 can be obtained according to the geometric relationship, as shown in the following:

$$
\left(x_{0}, y_{0}\right)=\left(-\sqrt{(R+r)^{2}-(d+r)^{2}}, r\right) \text {. }
$$

Friction is ignored, considering every moment is at the static equilibrium state when frame 2 decelerates.

The external force $F$ that acts on $W$ is completely transformed into the elastic potential energy $U$ of the main and horizontal springs.
Considering that main spring 1 and the horizontal spring experience precompression, the following then applies when the coordinates of the center of roller 3 are $(x, y)$ :

$$
\begin{aligned}
U= & k_{1} u_{1}\left(x-x_{0}\right)+\frac{1}{2} k_{1}\left(x-x_{0}\right)^{2}+k_{2} u_{2}\left(y-y_{0}\right) \\
& +\frac{1}{2} k_{2}\left(y-y_{0}\right)^{2} .
\end{aligned}
$$

Roller 3 rolls on the edge of curved edge component 5 ; thus, the coordinates of the center of roller 3 satisfy the following equation:

$$
x^{2}+(y+d)^{2}=(R+r)^{2} .
$$

By differentiating (3) with respect to coordinate $x$, force $F$ is expressed as

$$
\begin{aligned}
F & =\frac{d W}{d x} \\
& =k_{1} u_{1}+k_{1}\left(x-x_{0}\right)+k_{2} u_{2} y^{\prime}+k_{2}\left(y-y_{0}\right) y^{\prime},
\end{aligned}
$$

where

$$
y^{\prime}=\frac{d y}{d x}=-\frac{x}{\sqrt{(R+r)^{2}-x^{2}}} .
$$

By differentiating (5) with respect to coordinate $x$, stiffness $k$ is expressed as

$$
k=k_{1}+k_{2} u_{2} y^{\prime \prime}+k_{2} y^{\prime 2}+k_{2}\left(y-y_{0}\right) y^{\prime \prime},
$$

where

$$
y^{\prime \prime}=\frac{d y^{\prime}}{d x}=-\frac{(R+r)^{2}}{\sqrt{\left[(R+r)^{2}-x^{2}\right]^{3}}} .
$$




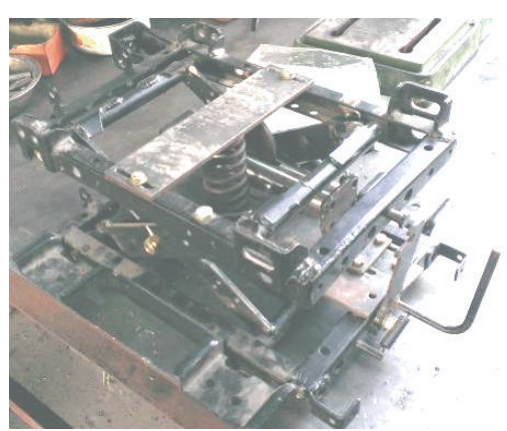

(a)

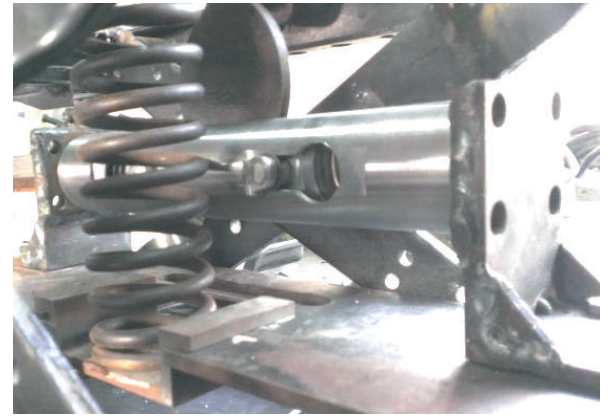

(b)

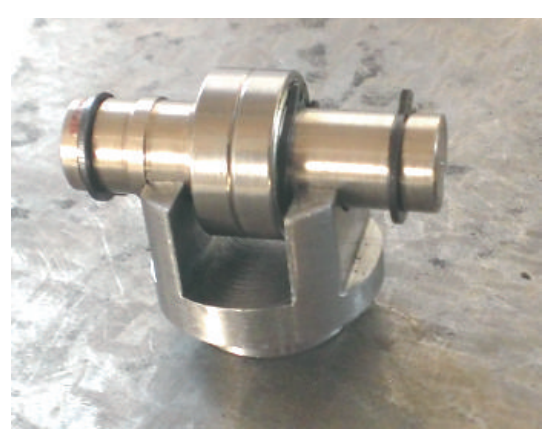

(c)

Figure 3: Physical prototype.

The following is obtained by substituting (4), (6), and (8) into (7):

$$
k=k_{1}-k_{2}+k_{2}\left(d+r-u_{2}\right) \frac{(R+r)^{2}}{\sqrt{\left[(R+r)^{2}-x^{2}\right]^{3}}} .
$$

The following dimensionless parameters are conveniently defined:

$$
\begin{aligned}
\widehat{R} & =\frac{R}{R}=1, \\
\widehat{r} & =\frac{r}{R}, \\
\widehat{d} & =\frac{d}{R}, \\
\widehat{u}_{1} & =\frac{u_{1}}{R}, \\
\widehat{u}_{2} & =\frac{u_{2}}{R}, \\
\widehat{F} & =\frac{F}{k_{2} R}, \\
\widehat{k_{1}} & =\frac{k_{1}}{k_{2}}, \\
\widehat{x} & =\frac{x}{R}, \\
\widehat{y} & =\frac{y}{R} .
\end{aligned}
$$

Subsequently,

$$
\begin{aligned}
\left(\widehat{x}_{0}, \widehat{y}_{0}\right) & =\left(-\sqrt{(1+\widehat{r})^{2}-(\widehat{d}+\widehat{r})^{2}}, \widehat{r}\right), \\
\hat{y} & =\sqrt{(1+\widehat{r})^{2}-\widehat{x}^{2}}-\widehat{d},
\end{aligned}
$$

$$
\begin{aligned}
\widehat{F}= & \widehat{k}_{1} \widehat{u}_{1}+\widehat{k}_{1}\left(\widehat{x}-\widehat{x}_{0}\right)-\widehat{u}_{2} \frac{\widehat{x}}{\sqrt{(1+\widehat{r})^{2}-\widehat{x}^{2}}} \\
& -\left(\hat{y}-\widehat{y}_{0}\right) \frac{\widehat{x}}{\sqrt{(1+\widehat{r})^{2}-\widehat{x}^{2}}}, \\
\widehat{k}= & \widehat{k}_{1}-1+\left(\hat{d}+\widehat{r}-\widehat{u}_{2}\right) \frac{(1+\widehat{r})^{2}}{\sqrt{\left[(1+\widehat{r})^{2}-\widehat{x}^{2}\right]^{3}}} .
\end{aligned}
$$

According to (14), $\widehat{k}$ has the minimum value $\widehat{k}_{\text {min }}$ when $\widehat{x}=0$ :

$$
\widehat{k}_{\min }=\widehat{k}_{1}-1+\frac{\widehat{d}+\widehat{r}-\widehat{u}_{2}}{1+\widehat{r}} .
$$

Let $\widehat{k}_{\text {min }}=0$, and then the following applies to obtain the mechanism with zero-stiffness point:

$$
\widehat{k}_{1}=1-\frac{\widehat{d}+\widehat{r}-\widehat{u}_{2}}{1+\widehat{r}} .
$$

When $\widehat{k}_{1}, \widehat{d}, \widehat{r}$, and $\widehat{u}_{2}$ satisfy (16), the mechanism evidently exhibits zero-stiffness point.

2.3. Static Characteristic Experimental Verification. A nonlinear seat suspension physical prototype is fabricated based on the aforementioned theory, as shown in Figure 3. The whole suspension is shown in Figure 3(a); the magnified negative stiffness mechanism is shown in Figure 3(b); and the roller, small shaft, and guide block assembly is shown in Figure 3(c).

A test system for the seat suspension static characteristic is used, as shown in Figure 4. The figure also shows that a nonlinear seat suspension is placed on a platform. An electric cylinder is fixed on a frame and is loaded on the upper frame of the seat suspension. The loading velocity is $20 \mathrm{~N} / \mathrm{s}$. A force sensor is installed on the loading side of the electric cylinder that generates the force value. A displacement sensor is installed in the electric cylinder. The static force-displacement characteristic is then obtained, as shown in Figure 5.

The measurement and theory curves are assembled, as shown in Figure 5, which shows that the loading curve is 

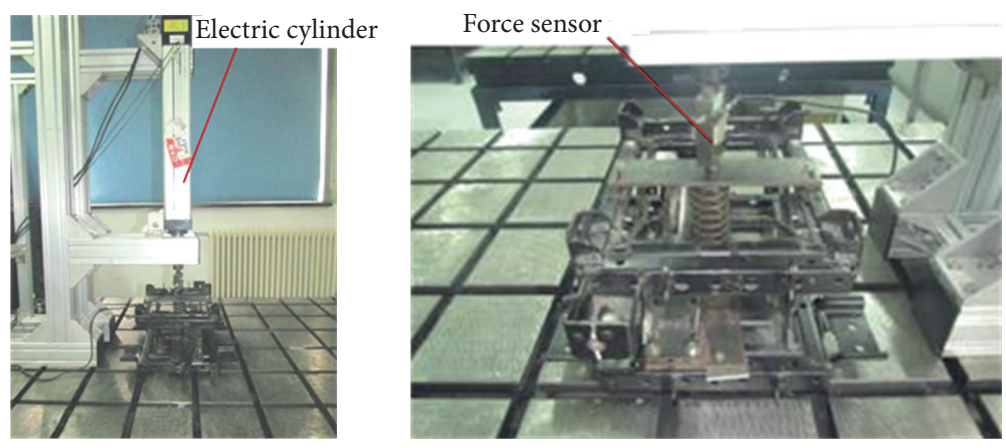

FIGURE 4: Static characteristic experiment.

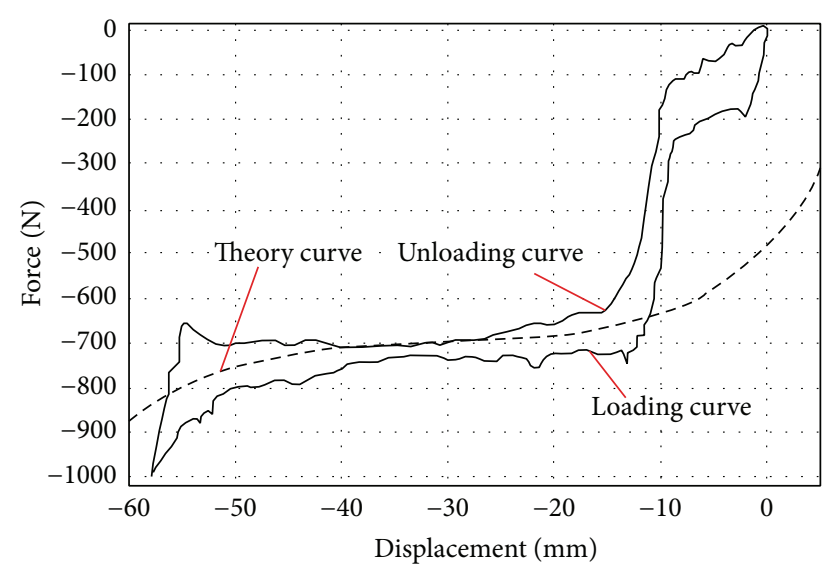

FIgURE 5: Static force-displacement characteristic curve.

lower than the unloading curve, and the two measurement curves are close to the theory curve in the middle segment. However, a large divergence is observed at the end of the curves because the initial assembly position of the physical prototype is different from theory, although the middle segment can also verify both theory and experiment.

\section{Dynamic Characteristic Modeling}

3.1. Seat-Human System Modeling. A seat and a human constitute a system, in which the dynamic characteristics of a seat are correlated with the human body; many sitting human mechanic models have been developed, including the lumped mass, multibody, and finite element models [23-27]. Rakheja et al. studied the driver-seat-suspension system by analytical and experimental methods. Vertical seat suspension systems were characterized by a generalized two-degree-of-freedom model incorporating nonlinearities due to shock absorber damping, linkage friction, and bump stops. Human body models of varying complexities, derived from the mechanical impedance date, were discussed and integrated to the nonlinear seat suspension model to derive a coupled driver-seatsuspension model [28]. Liang and Chiang studied lumped parameter models in seated human subjects without backrest support under vertical vibration excitation. In Liang and Chiang's study, all models were analyzed systematically and were validated by synthesizing various experimental data from published literature. Based on the analytical study and experimental validation, the $4 \mathrm{DOF}$ model developed by Wan and Schimmels[30] best fits existing test results and is recommended to study biodynamic responses of seated human subjects under vertical whole body vibration [29].

The 4DOF model [30] is coupled with a nonlinear suspension seat, and then a nonlinear seat-human system dynamic model is created in this research, as shown in Figure 6. The seat-human system model has five degrees of freedom: $Z_{1}, Z_{2}, Z_{3}, Z_{4}$, and $Z_{5}$; the equilibrium position is the origin of the coordinate system; and the vehicle floor vibration displacement input is $Z_{0}$. In Figure $6, m_{1}$ is the mass of the seat cushion and back; $m_{2}$ is the mass of the lower torso; $m_{3}$ is the mass of the abdominal visceral; $m_{4}$ is the mass of the upper torso; $m_{5}$ is the mass of the head and neck; $c_{1}$ is the damping of the seat suspension; $k_{2}$ and $c_{2}$ are the stiffness and damping of the foam of the cushion, respectively; $k_{3}$ and $c_{3}$ are the stiffness and damping between the abdominal visceral and lower torso, respectively; $k_{4}$ and $c_{4}$ are the stiffness and damping between the upper and lower torsos, respectively; $k_{5}$ and $c_{5}$ are the stiffness and damping between the abdominal visceral and upper torso, respectively; and $k_{6}$ and $c_{6}$ are the upper torso, and head and neck, respectively.

$F(u)$ is the static characteristic of the nonlinear seat suspension, which is derived from the static characteristic model. In (5), the original point of the coordinate system is changed to the equilibrium position, and then (17) can be obtained. Consider

$$
\begin{aligned}
F(u)= & k_{11} u+k_{22} u_{2}\left[-\frac{u}{\sqrt{(R+r)^{2}-u^{2}}}\right] \\
& +k_{22}\left[\sqrt{(R+r)^{2}-u^{2}}-d-r\right] \\
& \cdot\left[-\frac{u}{\sqrt{(R+r)^{2}-u^{2}}}\right] .
\end{aligned}
$$

Based on Newton's second law, five-degree-of-freedom seat-human dynamic model is created as follows:

$$
\begin{aligned}
m_{1} \ddot{Z}_{1}= & F\left(Z_{0}-Z_{1}\right)+c_{1}\left(\dot{Z}_{0}-\dot{Z}_{1}\right)-k_{2}\left(Z_{1}-Z_{2}\right) \\
& -c_{2}\left(\dot{Z}_{1}-\dot{Z}_{2}\right)
\end{aligned}
$$


TABLE 1: Table of parameters.

\begin{tabular}{|c|c|c|c|c|c|c|}
\hline \multirow{2}{*}{ Mass (kg) } & $m_{1}$ & $m_{2}$ & $m_{3}$ & $m_{4}$ & $m_{5}$ & \\
\hline & 9.33 & 36 & 5.5 & 15 & 4.17 & \\
\hline \multirow{2}{*}{ Damping (Ns/m) } & $c_{1}$ & $c_{2}$ & $c_{3}$ & $c_{4}$ & $c_{5}$ & $c_{6}$ \\
\hline & 100 & 2475 & 330 & 200 & 909.1 & 250 \\
\hline \multirow{2}{*}{ Stiffness (N/m) } & $k_{2}$ & $k_{3}$ & $k_{4}$ & $k_{5}$ & $k_{6}$ & \\
\hline & 49,340 & 20,000 & 10,000 & 192,000 & 134,400 & \\
\hline \multirow{2}{*}{ Parameters of nonlinear suspension } & $k_{11}$ & $k_{22}$ & $R$ & $r$ & $d$ & $u_{2}$ \\
\hline & $17,500 \mathrm{~N} / \mathrm{m}$ & $36,000 \mathrm{~N} / \mathrm{m}$ & $38.6 \mathrm{~mm}$ & $10.5 \mathrm{~mm}$ & $18 \mathrm{~mm}$ & $2 \mathrm{~mm}$ \\
\hline
\end{tabular}

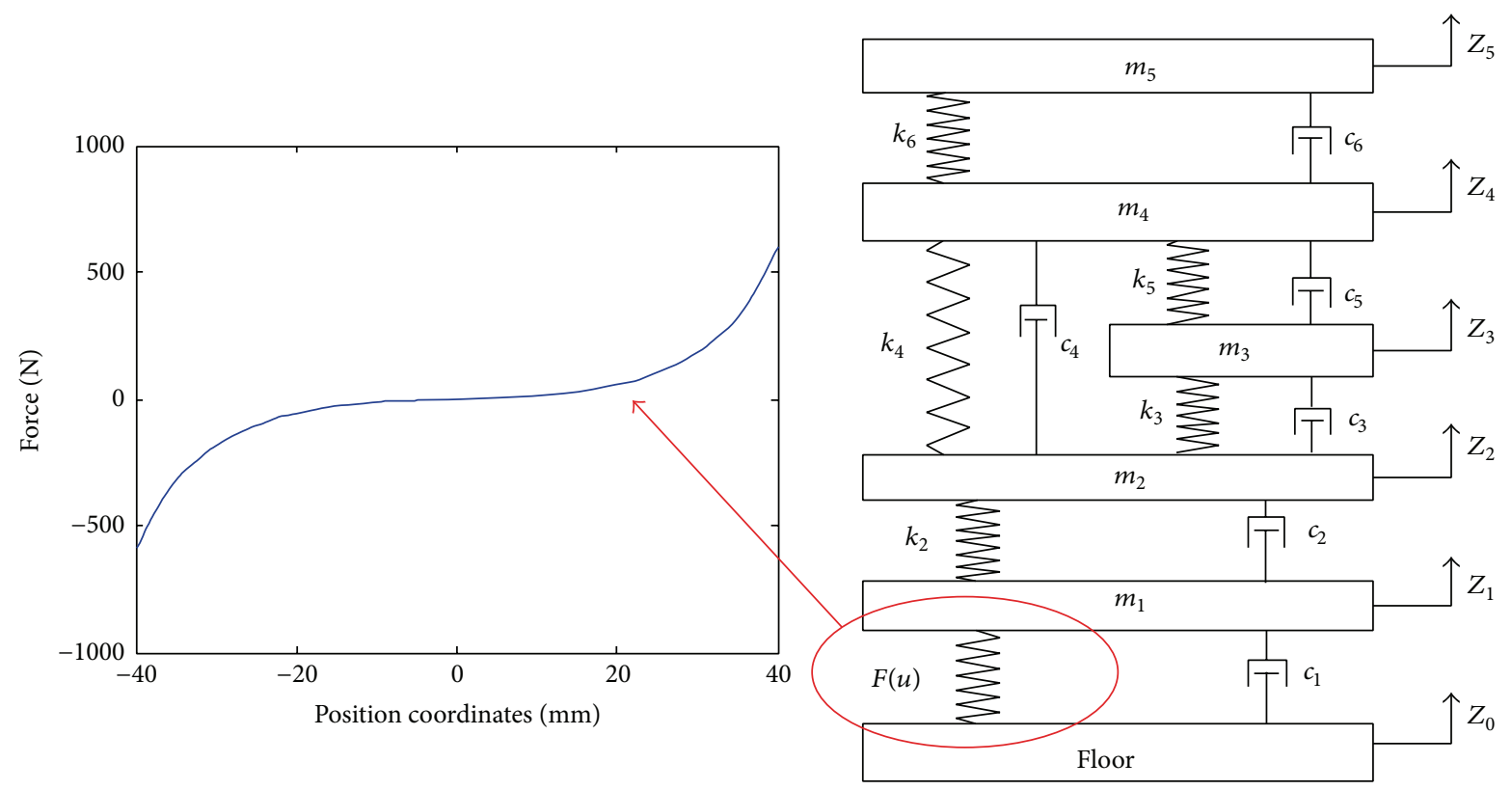

(a)

(b)

Figure 6: Coupling of the four degrees of human model and nonlinear suspension seat model. (a) Force-displacement characteristics. (b) Dynamic model of the seat-human system.

$$
\begin{aligned}
m_{2} \ddot{Z}_{2}= & k_{2}\left(Z_{1}-Z_{2}\right)+c_{2}\left(\dot{Z}_{1}-\dot{Z}_{2}\right)-k_{3}\left(Z_{2}-Z_{3}\right) \\
& -c_{3}\left(\dot{Z}_{2}-\dot{Z}_{3}\right)-k_{4}\left(Z_{2}-Z_{4}\right) \\
& -c_{4}\left(\dot{Z}_{2}-\dot{Z}_{4}\right), \\
m_{3} \ddot{Z}_{3}= & k_{3}\left(Z_{2}-Z_{3}\right)+c_{3}\left(\dot{Z}_{2}-\dot{Z}_{3}\right)-k_{5}\left(Z_{3}-Z_{4}\right) \\
& -c_{5}\left(\dot{Z}_{3}-\dot{Z}_{4}\right), \\
m_{4} \ddot{Z}_{4}= & k_{4}\left(Z_{2}-Z_{4}\right)+c_{4}\left(\dot{Z}_{2}-\dot{Z}_{4}\right)+k_{5}\left(Z_{3}-Z_{4}\right) \\
& +c_{5}\left(\dot{Z}_{3}-\dot{Z}_{4}\right)-k_{6}\left(Z_{4}-Z_{5}\right) \\
& -c_{6}\left(\dot{Z}_{4}-\dot{Z}_{5}\right), \\
m_{5} \ddot{Z}_{5}= & k_{6}\left(Z_{4}-Z_{5}\right)+c_{6}\left(\dot{Z}_{4}-\dot{Z}_{5}\right) .
\end{aligned}
$$

3.2. Seat-Human System Dynamic Model Created through the ADAMS Software. A multibody dynamic model with the same parameters is created using the ADAMS software to verify the above seat-human system dynamic model, as shown in Figure 7. The human body model is composed of four masses and spring dampers, as shown in Figure 7(a). The nonlinear suspension model is shown in Figure 7(b), in which a line-line constraint is created between the roller and the curved edge plate. A spring damper is created between the human body model and the nonlinear suspension to simulate the stiffness and damping of the foam pad.

3.3. Model Validation. The mathematical model is solved using ODE45 of the MATLAB software, through which displacement versus time and velocity versus time curves are obtained. The model parameters are shown in Table 1.

The excitation is $Z_{0}=10 \times \sin (2 \times \pi \times f \times t)$, where $f$ is the vibration frequency of the vehicle floor. The computation time is $20 \mathrm{~s}$, and human hip displacement versus time curves are extracted. The response curve when the vehicle floor vibration is $1 \mathrm{~Hz}$ is shown in Figure 8(a); the response curve when the vibration frequency of the vehicle floor is $4 \mathrm{~Hz}$ is shown in Figure 8(b). 


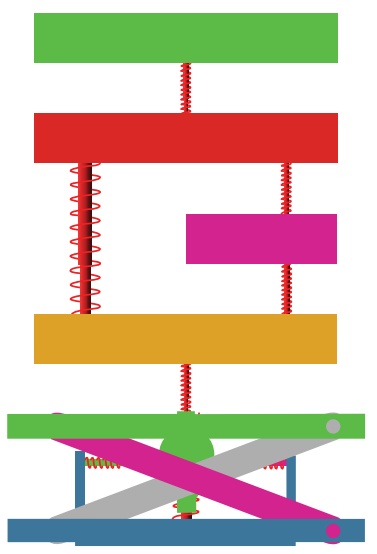

(a)

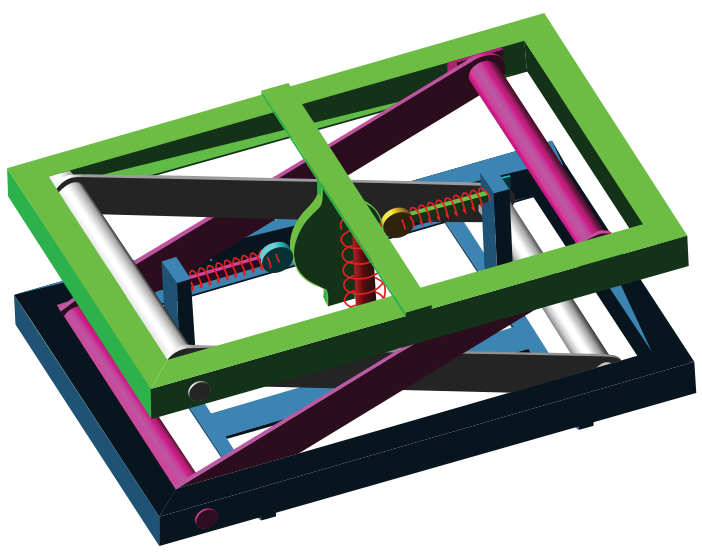

(b)

Figure 7: ADAMS dynamic model of the seat-human system. (a) Dynamic model of the coupled system. (b) Nonlinear suspension model.

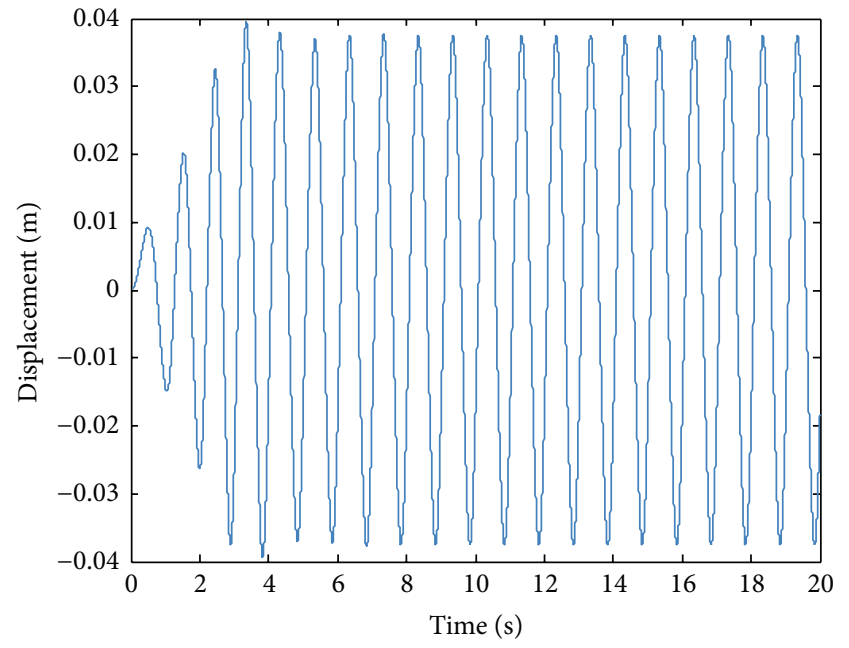

(a)

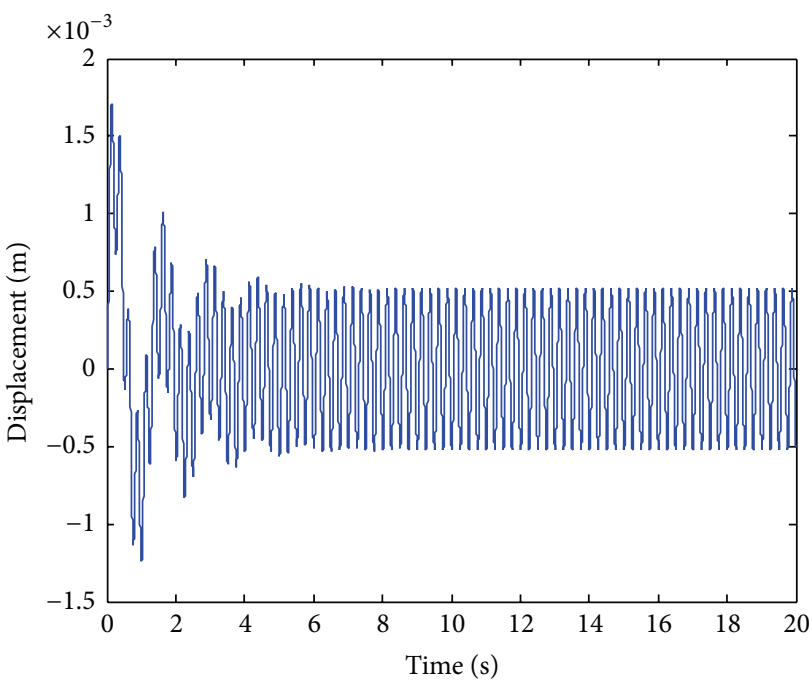

(b)

Figure 8: Responses from the mathematical model. (a) Hip displacement response when the excitation frequency is $1 \mathrm{~Hz}$. (b) Hip displacement response when the excitation frequency is $4 \mathrm{~Hz}$.

A dynamic model with the same parameters is created using the ADAMS software, and the human hip displacement response is shown in Figure 9. The computation time is $20 \mathrm{~s}$, and human hip displacement versus time curves are extracted. The response curve when the vibration frequency of the vehicle floor is $1 \mathrm{~Hz}$ is shown in Figure 9(a), while Figure 9(b) shows the response curve when the vibration frequency of the vehicle floor is $4 \mathrm{~Hz}$.

By comparing Figures 8 and 9, the human hip displacement response curves are evidently consistent, which verifies the accuracy of the models established.

The static characteristic model is validated by experiment, whereas the seat-man dynamic model is validated by the ADAMS software. The dynamics of nonlinear suspension are validated with weight stack, not human, in the experiment, shown in Figure 10.

\section{Results and Discussions}

4.1. Static Characteristics. According to (13), (14), (15), (16), (18a), (18b), (18c), (18d), and (18e), the influences of $\widehat{r}, \widehat{d}, \widehat{u}_{2}$, and $\widehat{u}_{1}$ on the $\widehat{F}-\widehat{x}$ and $\widehat{k}-\widehat{x}$ curves are researched. Four cases are investigated. The other parameters remain fixed when a parameter is changed. The basic values of $\widehat{r}, \widehat{d}, \widehat{u}_{2}$, and $\widehat{u}_{1}$ are shown in Table 2.

\subsection{1. $\hat{r}$ Is Changed, While the Other Parameters Remain Fixed.} The influence of $\hat{r}$ on the characteristic curves is shown in Figure 11 . The influences of $\widehat{r}$ on the $\widehat{F}-\widehat{x}$ and $\widehat{k}-\widehat{x}$ curves are shown in Figures 11(a) and 11(b), respectively. Given the increment of $\widehat{r}$, the $\widehat{F}-\widehat{x}$ curve descends, and the span of the low stiffness increases. The two curves flatten. 
TABLE 2: Configurative parameters.

\begin{tabular}{lcccc}
\hline Parameter & (1) Change in the value of $\widehat{r}$ & (2) Change in the value of $\widehat{d}$ & (3) Change in the value of $\widehat{u}_{2}$ & $(4)$ Change in the value of $\widehat{u}_{1}$ \\
\hline$\widehat{r}$ & $0,1.0,2.0,3.0,4.0$, and 5.0 & 0.27 & 0.27 & 0.27 \\
$\widehat{d}$ & 0.66 & $0.08,0.25,0.42,0.59$, and 0.76 & 0.66 & 0.66 \\
$\widehat{u}_{2}$ & 0 & 0 & $0,1.0,2.0,3.0,4.0$, and 5.0 & 0 \\
$\widehat{u}_{1}$ & 0 & 0 & 0 & $0,1.0,2.0,3.0,4.0$, and 5.0 \\
\hline
\end{tabular}

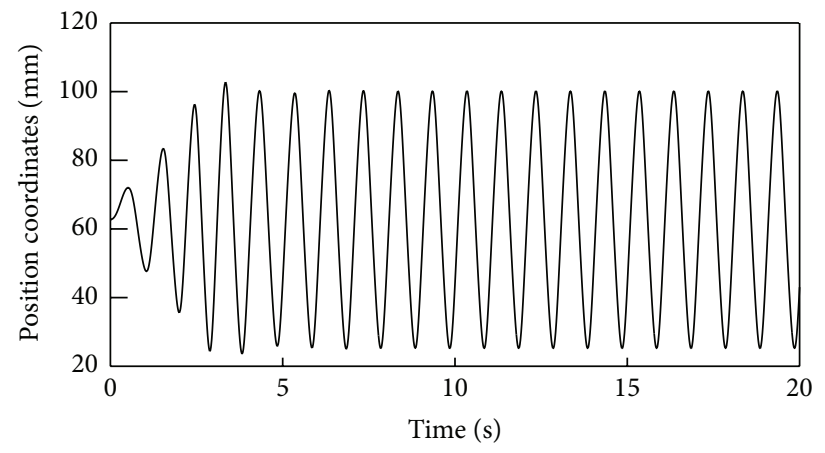

(a)

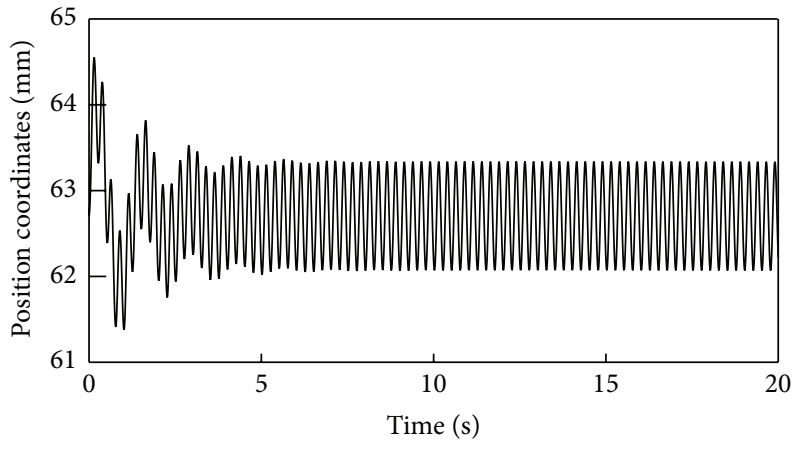

(b)

Figure 9: Responses from the ADAMS Model. (a) Hip displacement when the excitation frequency is $1 \mathrm{~Hz}$. (b) Hip displacement response when the excitation frequency is $4 \mathrm{~Hz}$.

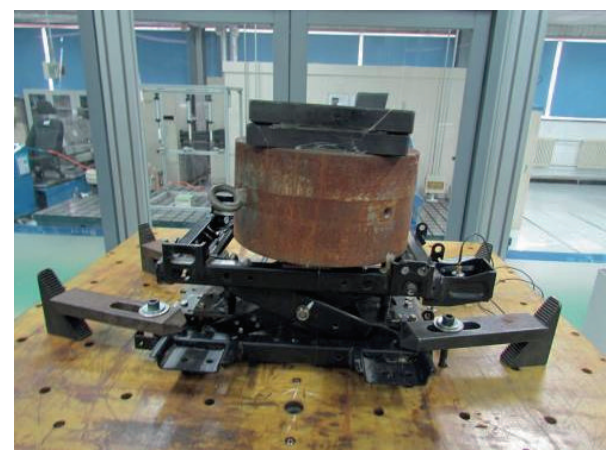

FIGURE 10: Test validating the dynamic of nonlinear suspension.

4.1.2. $\widehat{d}$ Is Changed, While the Other Parameters Are Fixed. The influences of $\hat{d}$ on the characteristic curves are shown in Figure 11. The influence of $\widehat{d}$ on the $\widehat{F}-\widehat{x}$ and $\widehat{k}-\widehat{x}$ curves is shown in Figures 11(c) and 11(d), respectively. Given the increment of $\widehat{d}$, the $\widehat{F}-\widehat{x}$ curve descends and the low stiffness span decreases. The two curves then flatten.

4.1.3. $\widehat{u}_{2}$ Is Changed, While the Other Parameters Are Fixed. The influences of $\widehat{u}_{2}$ on the characteristic curves are shown in Figure 11. The influences of $\widehat{u}_{2}$ on the $\widehat{F}-\widehat{x}$ and $\widehat{k}-\widehat{x}$ curves are shown in Figures 11(e) and 11(f), respectively. As $\widehat{u}_{2}$ increases, the $\widehat{F}-\widehat{x}$ curve ascends, and both ends of the curved positive stiffness value reduce and gradually become negative values. When $\widehat{u}_{2}$ is provided with an appropriate value, the $\widehat{F}-\widehat{x}$ curve changes from parallel to the horizontal axis, the $\widehat{k}-\widehat{x}$ curve changes from parallel to the horizontal axis, and the values become zero (as presented by the horizontal dashed line in Figure 11(f)).

4.1.4. $\widehat{u}_{1}$ Is Changed, While the Other Parameters Are Fixed. The influence of $\widehat{u}_{1}$ on the characteristic curves is shown in Figure $11(\mathrm{~g})$. The figure shows the influence of $\widehat{u}_{1}$ on the $\widehat{F}-\widehat{x}$ curve. As $\widehat{u}_{1}$ increases, the $\widehat{F}-\widehat{x}$ curve ascends in parallel, but $\widehat{u}_{1}$ does not affect the $\widehat{k}-\widehat{x}$ curve.

Based on the examination of Figures 11(e) and 11(f), and (16), $\widehat{k} \equiv 0$ when $\widehat{k}_{1}=1$ and $\widehat{d}+\widehat{r}=\widehat{u}_{2}$; the mechanism has real zero-stiffness characteristic.

In addition, nonlinear seat suspension performs best when a driver's weight is certain. The performance worsens as a driver's weight changes. Based on the analysis of Figure 11( $\mathrm{g}$ ) and (15), $\widehat{u}_{1}$ is proportional to $\widehat{F}$; as shown in (16), $\widehat{u}_{1}$ does not affect $\widehat{k} . \widehat{u}_{1}$ can be changed when a driver's weight changes for the suspension to always be in the best isolation state.

\subsection{Dynamic Characteristics}

4.2.1. Influences of Static Stiffness Characteristics of Nonlinear Suspension on Displacement Transmissibility. Only $k_{11}$ is changed by $1,700,22,000$, and $27,000 \mathrm{~N} / \mathrm{m}$ based on the seathuman dynamic model with the parameters in Table 1 , and the three static force-displacement characteristic curves are shown in Figure 12(a). The human hip displacement transmissibility curves corresponding to the force-displacement characteristic curves are shown in Figure 12(b), where the curve intermediate area is gentler, the stiffness is lower, the peak resonant frequency corresponding to the displacement 


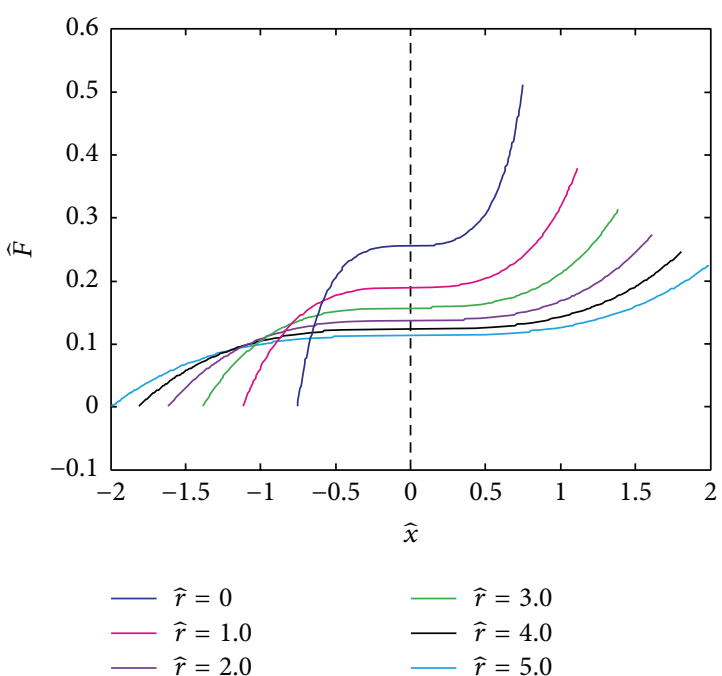

(a)

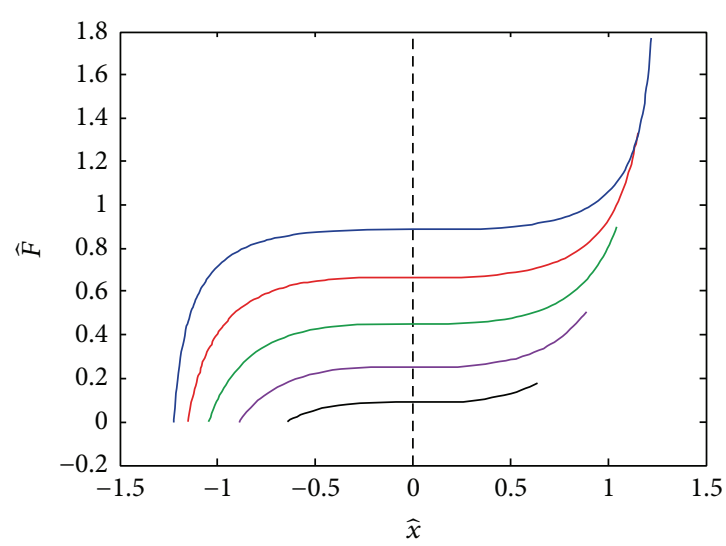

$$
\begin{array}{ll}
-\widehat{d}=0.08 & -\widehat{d}=0.59 \\
-\widehat{d}=0.25 & -\widehat{d}=0.76
\end{array}
$$

(c)

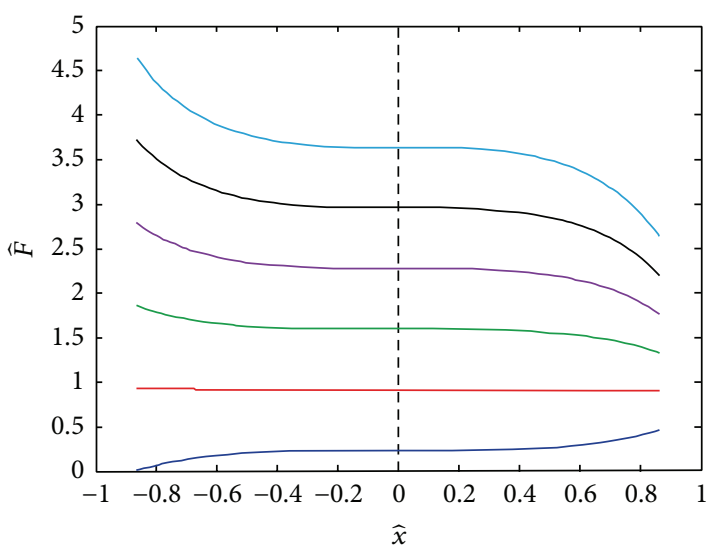
$-\widehat{u}_{2}=0$
$-\widehat{u}_{2}=1.0$
$-\widehat{u}_{2}=2.0$
$\begin{aligned}-\widehat{u}_{2} & =3.0 \\ -\widehat{u}_{2} & =4.0 \\ -\widehat{u}_{2} & =5.0\end{aligned}$

(e)

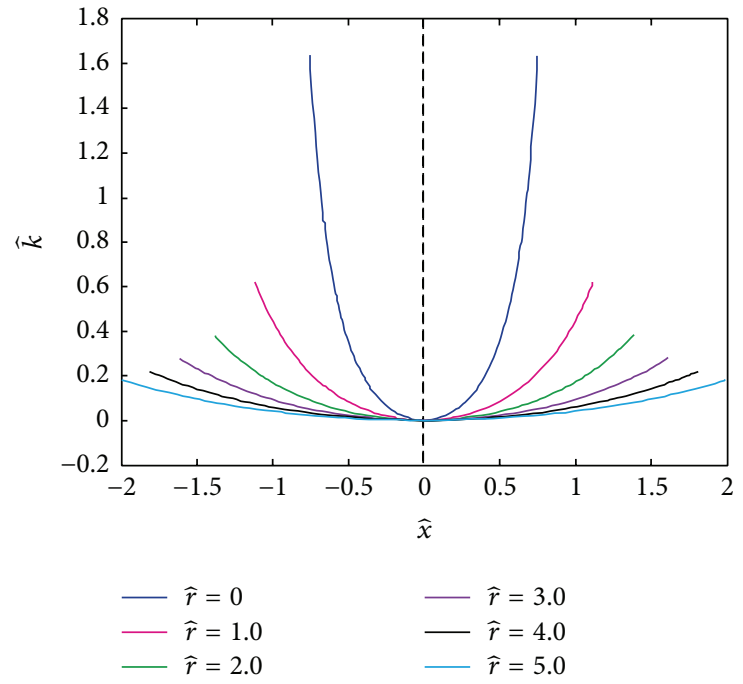

(b)
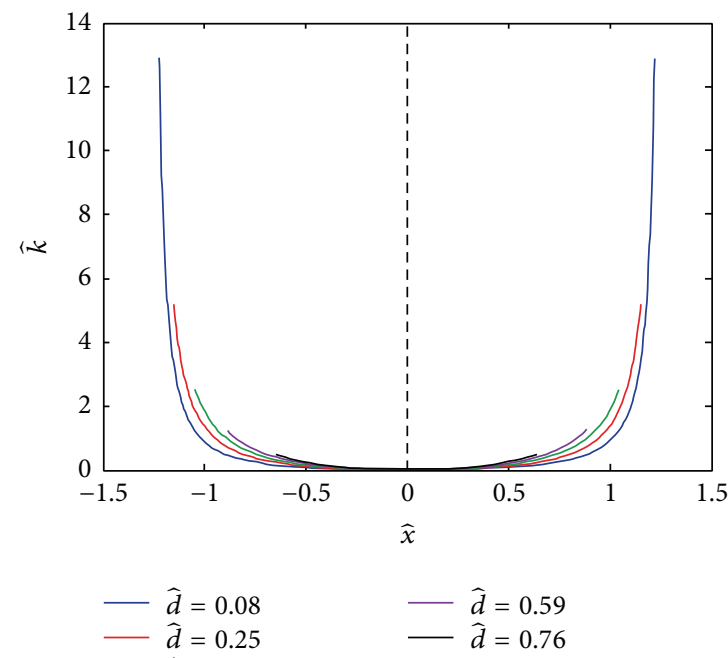

(d)
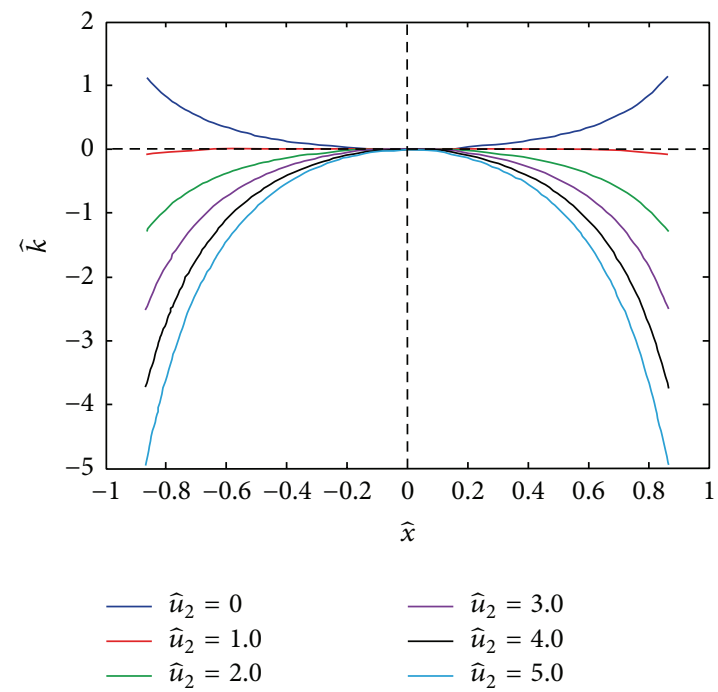

(f)

FIGURE 11: Continued. 


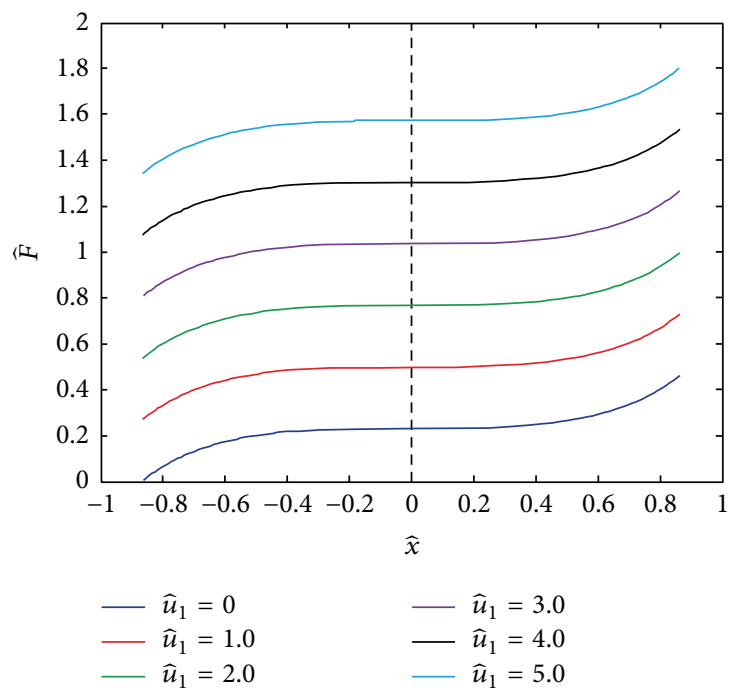

(g)

Figure 11: Influences of the parameters on the characteristic curves. (a), (c), (e), and (g) are influences of $\widehat{r}, \widehat{d}, \widehat{u}_{2}$, and $\widehat{u}_{1}$ on the $\widehat{F}-\widehat{x}$ curve, respectively; (b), (d), and (f) are influences of $\widehat{r}, \widehat{d}$, and $\widehat{u}_{2}$ on the $\widehat{k}-\widehat{x}$ curve, respectively.

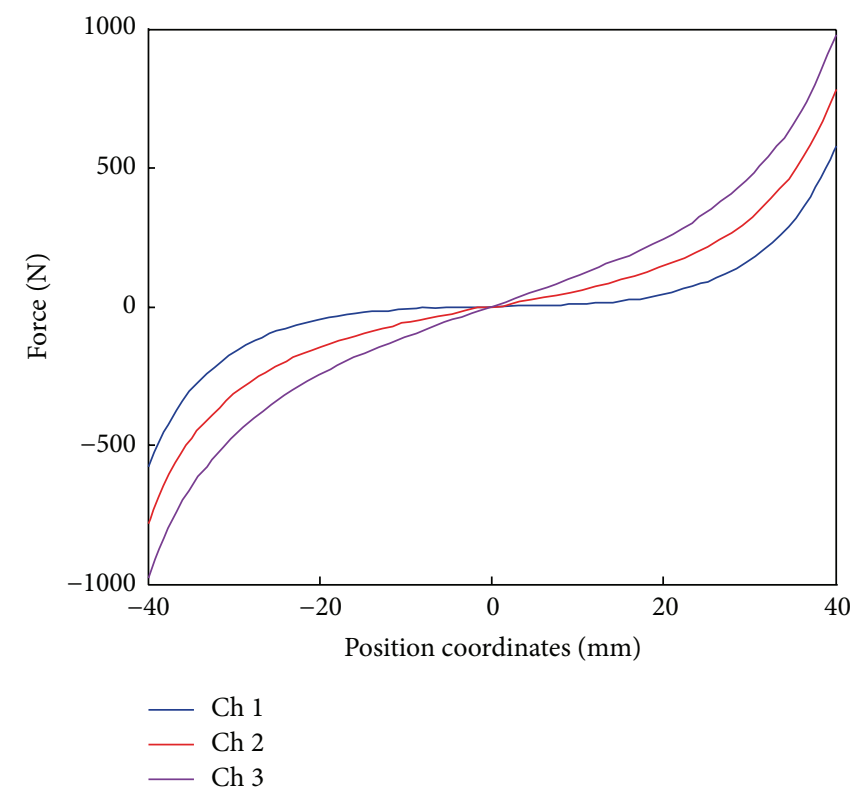

(a)

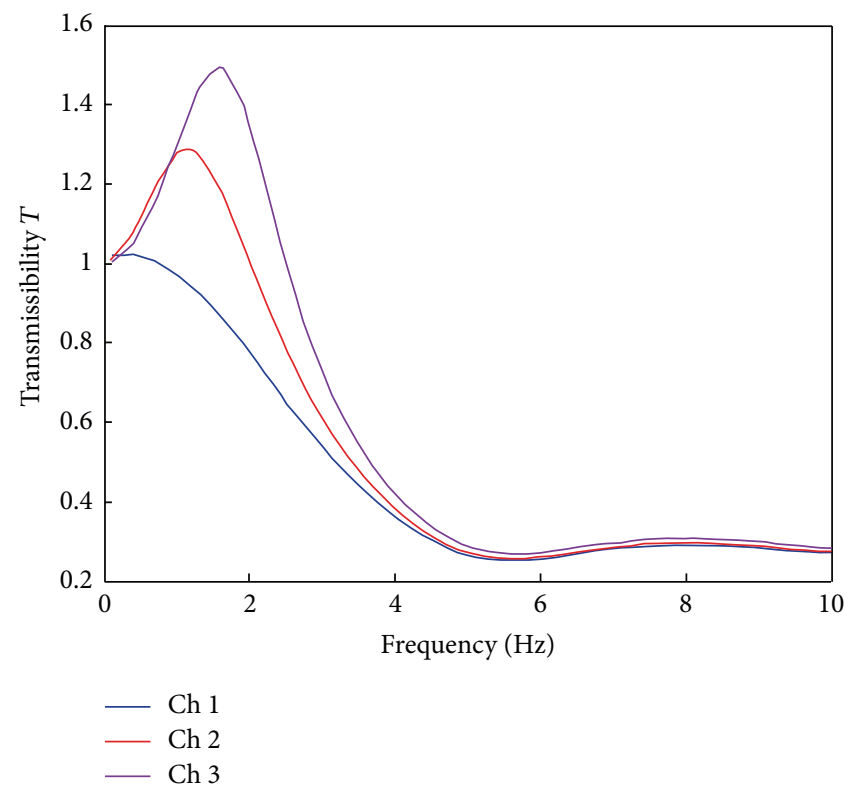

(b)

Figure 12: Influences of nonlinear stiffness characteristics on displacement transmissibility. (a) Force-displacement characteristics. (b) Displacement transmissibility.

transmissibility curves is lower, and the resonance peak value is smaller. The three displacement transmissibility curves almost coincide when the excitation frequency is more than $6 \mathrm{~Hz}$.

4.2.2. Influence of Nonlinear Suspension Damping on Displacement Transmissibility. $c_{1}$ is changed by $100,1,000$, and $2,000 \mathrm{Ns} / \mathrm{m}$ when the force-displacement characteristic curve exhibits characteristic 1 ; the displacement transmissibility is shown in Figure 13(a). The stiffness of the work area of characteristic 1 curve is low; the transmissibility of the resonance region is larger than 1 given minimal damping; the transmissibility of the resonance region reduces or the whole transmissibility curve becomes less than 1 when damping increases; and the transmissibility of the nonresonant region rapidly rises as damping increases.

$c_{1}$ is changed by $100,1,000$, and $2,000 \mathrm{Ns} / \mathrm{m}$ when the force-displacement characteristic curve exhibits characteristic 1; the displacement transmissibility is shown in Figure 13 (b). $c_{1}$ is changed by $100,1,000$, and $2,000 \mathrm{Ns} / \mathrm{m}$ 


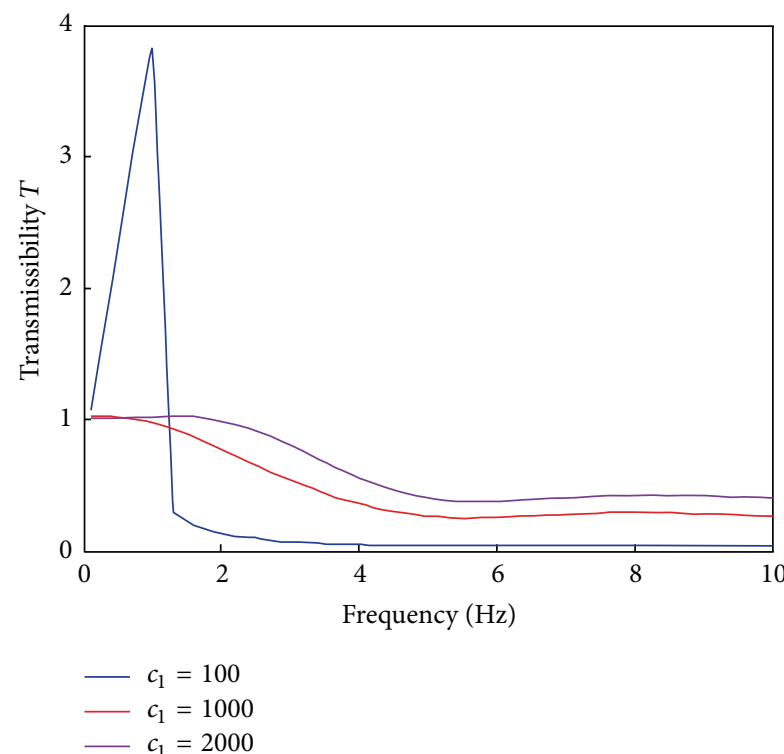

(a)

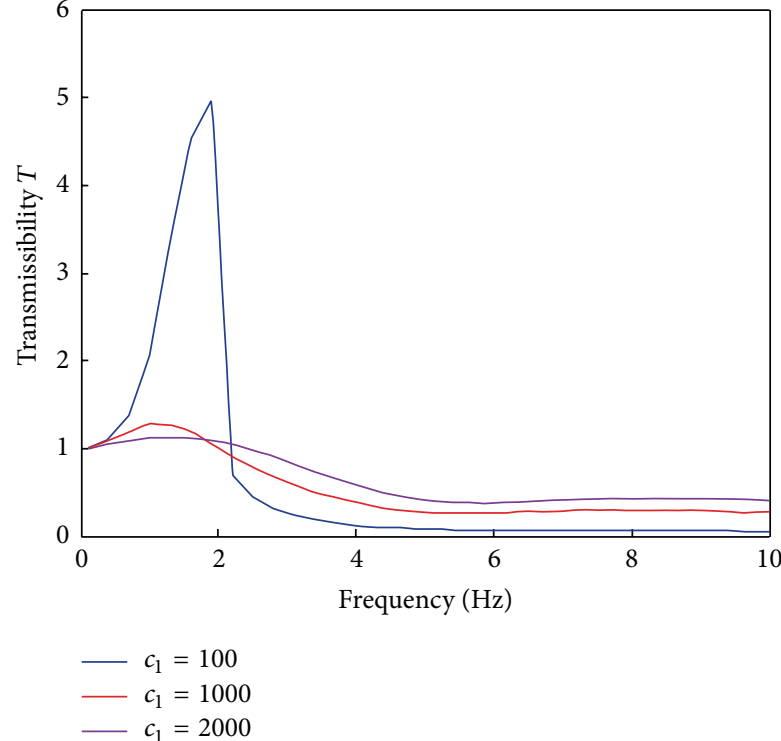

(b)

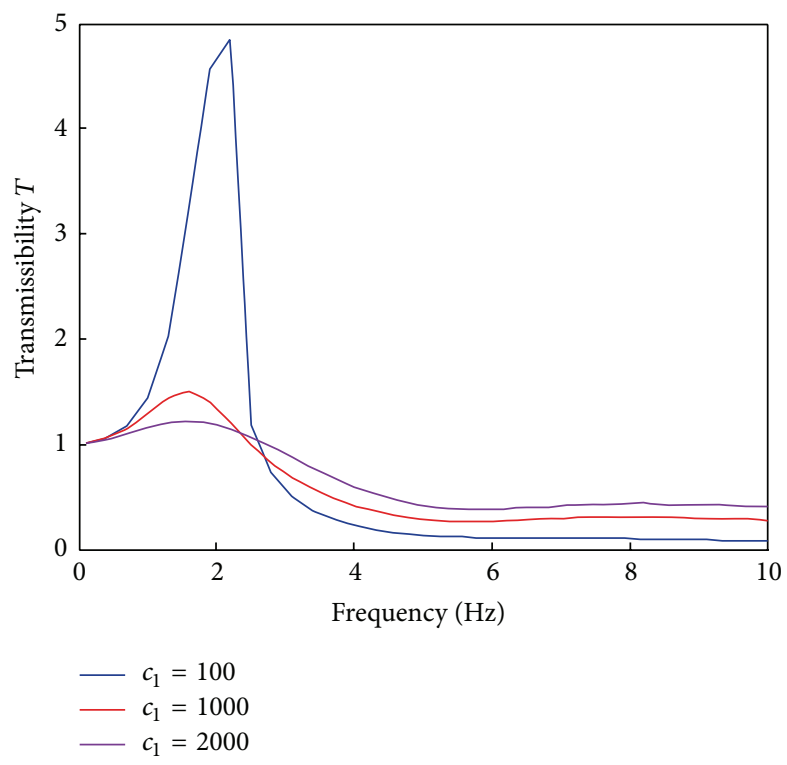

(c)

FIGURE 13: Matching of suspension force-displacement characteristics and damping influence on displacement transmissibility. (a) When the force-displacement characteristic exhibits characteristic 1. (b) When the force-displacement characteristic exhibits characteristic 2. (c) When the force-displacement characteristic exhibits characteristic 3.

when the force-displacement characteristic curve exhibits characteristic 3; the displacement transmissibility is shown in Figure 13(c). The stiffness of the work area of characteristic 2 and characteristic 3 curves is larger, and the displacement transmissibility curves change according to the same law when damping changes; the displacement transmissibility of the resonance region decreases rapidly as damping increases, whereas the displacement transmissibility of the nonresonance region increases.

Evidently, damping should be lower to match the nonlinear suspension with a low stiffness to obtain an excellent isolation effect. The stiffness of the work area of nonlinear suspension decreases, and performance is reduced if damping does not change.

\section{Conclusions}

A new nonlinear seat suspension structure was designed. Static and dynamic characteristics were studied. Static experiments verified the theoretical analysis results, and friction was found as the main factor that caused divergences between theory and measurement curves.

A mathematic model of static characteristics was established, and influences of key parameters on static 
characteristics were studied. When the parameters matched well, the whole suspension system could attain real zero stiffness and the nonlinear seat suspension performance could be changed through a driver's weight by changing the precompression of the main spring.

A 4DOF seated human model was coupled with nonlinear suspension, and then two seat-human system dynamic models were created and verified with each other. Displacement transmissibility characteristics were researched. The displacement transmissibility curve corresponded with the static characteristic curve of nonlinear suspension, in which the work area of the static characteristic curve was gentler, and the resonance frequency of the displacement transmissibility curve and the isolation minimum frequency were lower. Damping should correspond to static characteristics; given a flatter static characteristic curve, the corresponding suspension damping value should be smaller to avoid reducing the vibration isolation performance.

\section{Conflict of Interests}

The authors declare that no conflict of interests exists regarding the publication of this paper.

\section{Acknowledgments}

This work is partially supported by the National Natural Science Foundation of China $(51105169,51475206)$ and Jilin Province Science and Technology Development Plan Projects (20140204010GX).

\section{References}

[1] X. Zhao, M. Kremb, and C. Schindler, "Assessment of wheel loader vibration on the riding comfort according to ISO standards," Vehicle System Dynamics, vol. 51, no. 10, pp. 15481567, 2013.

[2] A. Pazooki, S. Rakheja, and D. Cao, "Modeling and validation of off-road vehicle ride dynamics," Mechanical Systems and Signal Processing, vol. 28, pp. 679-695, 2012.

[3] G. J. Stein and P. Múčka, "Study of simultaneous shock and vibration control by a fore-and-aft suspension system of a driver's seat," International Journal of Industrial Ergonomics, vol. 41, no. 5, pp. 520-529, 2011.

[4] A. Pazooki, D. Cao, S. Rakheja, and P.-É. Boileau, "Ride dynamic evaluations and design optimisation of a torsio-elastic off-road vehicle suspension," Vehicle System Dynamics, vol. 49, no. 9, pp. 1455-1476, 2011.

[5] P. Velmurugan, L. A. Kumaraswamidhas, and K. Sankaranarayanasamy, "Whole body vibration analysis for drivers of suspended cabin tractor semitrailer," Experimental Techniques, vol. 38, no. 2, pp. 47-53, 2014.

[6] Y. Wang, S. Li, C. Cheng, and X. Jiang, "Dynamic analysis of a high-static-low-dynamic-stiffness vibration isolator with time-delayed feedback control," Shock and Vibration, vol. 2015, Article ID 712851, 19 pages, 2015.

[7] X. Gao and Q. Chen, "Static and dynamic analysis of a high static and low dynamic stiffness vibration isolator utilising the solid and liquid mixture," Engineering Structures, vol. 99, pp. 205-213, 2015.
[8] L. Meng, J. Sun, and W. Wu, "Theoretical design and characteristics analysis of a quasi-zero stiffness isolator using a disk spring as negative stiffness element," Shock and Vibration, vol. 2015, Article ID 813763, 19 pages, 2015.

[9] I. Maciejewski, "Control system design of active seat suspensions," Journal of Sound and Vibration, vol. 331, no. 6, pp. 12911309, 2012.

[10] W. Sun, J. Li, Y. Zhao, and H. Gao, "Vibration control for active seat suspension systems via dynamic output feedback with limited frequency characteristic," Mechatronics, vol. 21, no. 1, pp. 250-260, 2011.

[11] G. J. Stein, P. Múčka, and T. P. Gunston, "A study of locomotive driver's seat vertical suspension system with adjustable damper," Vehicle System Dynamics, vol. 47, no. 3, pp. 363-386, 2009.

[12] S. B. Choi, J. H. Choi, Y. S. Lee, and M. S. Han, "Vibration control of an ER seat suspension for a commercial vehicle," Journal of Dynamic Systems, Measurement and Control, vol. 125, no. 1, pp. 60-68, 2003.

[13] M. Bouazara, M. J. Richard, and S. Rakheja, "Safety and comfort analysis of a 3-D vehicle model with optimal non-linear active seat suspension," Journal of Terramechanics, vol. 43, no. 2, pp. 97-118, 2006.

[14] T. D. Le and K. K. Ahn, "A vibration isolation system in low frequency excitation region using negative stiffness structure for vehicle seat," Journal of Sound and Vibration, vol. 330, no. 26, pp. 6311-6335, 2011.

[15] C.-M. Lee and V. N. Goverdovskiy, "Type synthesis of functiongenerating mechanisms for seat suspensions," International Journal of Automotive Technology, vol. 10, no. 1, pp. 37-48, 2009.

[16] S. T. Park, "Vibration isolation system with a unique low vibration frequency," US Patent Application 13/120,135, 2009.

[17] C. V. Jutte and S. Kota, "Design of single, multiple, and scaled nonlinear springs for prescribed nonlinear responses," Journal of Mechanical Design-Transactions of the ASME, vol. 132, no. 1, Article ID 0110031, 2010.

[18] A. Carrella, M. J. Brennan, and T. P. Waters, "Static analysis of a passive vibration isolator with quasi-zero-stiffness characteristic," Journal of Sound and Vibration, vol. 301, no. 3-5, pp. 678689, 2007.

[19] H.-J. Ahn, "Performance limit of a passive vertical isolator using a negative stiffness mechanism," Journal of Mechanical Science and Technology, vol. 22, no. 12, pp. 2357-2364, 2008.

[20] I. Kovacic, M. J. Brennan, and T. P. Waters, "A study of a nonlinear vibration isolator with a quasi-zero stiffness characteristic," Journal of Sound and Vibration, vol. 315, no. 3, pp. 700-711, 2008.

[21] A. Carrella, M. J. Brennan, T. P. Waters, and V. Lopes Jr., "Force and displacement transmissibility of a nonlinear isolator with high-static-low-dynamic-stiffness," International Journal of Mechanical Sciences, vol. 55, no. 1, pp. 22-29, 2012.

[22] L. T. Danh and K. K. Ahn, "Active pneumatic vibration isolation system using negative stiffness structures for a vehicle seat," Journal of Sound and Vibration, vol. 333, no. 5, pp. 1245-1268, 2014.

[23] V. K. Tewari and N. Prasad, "Three-DOF modelling of tractor seat-operator system," Journal of Terramechanics, vol. 36, no. 4, pp. 207-219, 1999.

[24] S. D. Smith, "Nonlinear resonance behavior in the human exposed to whole-body vibration," Shock and Vibration, vol. 1, no. 5, pp. 439-450, 1994.

[25] G. Mastinu, M. Gobbi, and M. Pennati, “Theoretical and experimental ride comfort assessment of a subject seated into 
a car," SAE International Journal of Passenger Cars: Mechanical Systems, vol. 3, no. 1, pp. 607-625, 2010.

[26] C.-C. Liang and C.-F. Chiang, "Modeling of a seated human body exposed to vertical vibrations in various automotive postures," Industrial Health, vol. 46, no. 2, pp. 125-137, 2008.

[27] S. H. Kim, J. K. Pyun, and H. Y. Choi, "Digital human body model for seat comfort simulation," International Journal of Automotive Technology, vol. 11, no. 2, pp. 239-244, 2010.

[28] S. Rakheja, Y. Afework, and S. Sankar, "An analytical and experimental investigation of the driver-seat-suspension system," Vehicle System Dynamics, vol. 23, no. 7, pp. 501-524, 1994.

[29] C.-C. Liang and C.-F. Chiang, "A study on biodynamic models of seated human subjects exposed to vertical vibration," International Journal of Industrial Ergonomics, vol. 36, no. 10, pp. 869890, 2006.

[30] Y. Wan and J. M. Schimmels, "A simple model that captures the essential dynamics of a seated human exposed to whole body vibration," in Advances in Bioengineering, vol. 31 of ASMEPublications-BED, pp. 333-334, ASME, 1995. 

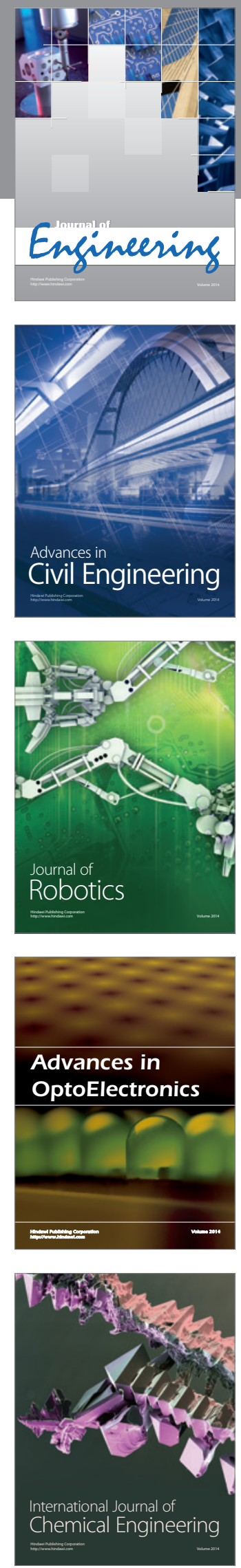

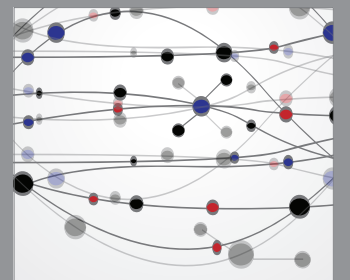

The Scientific World Journal
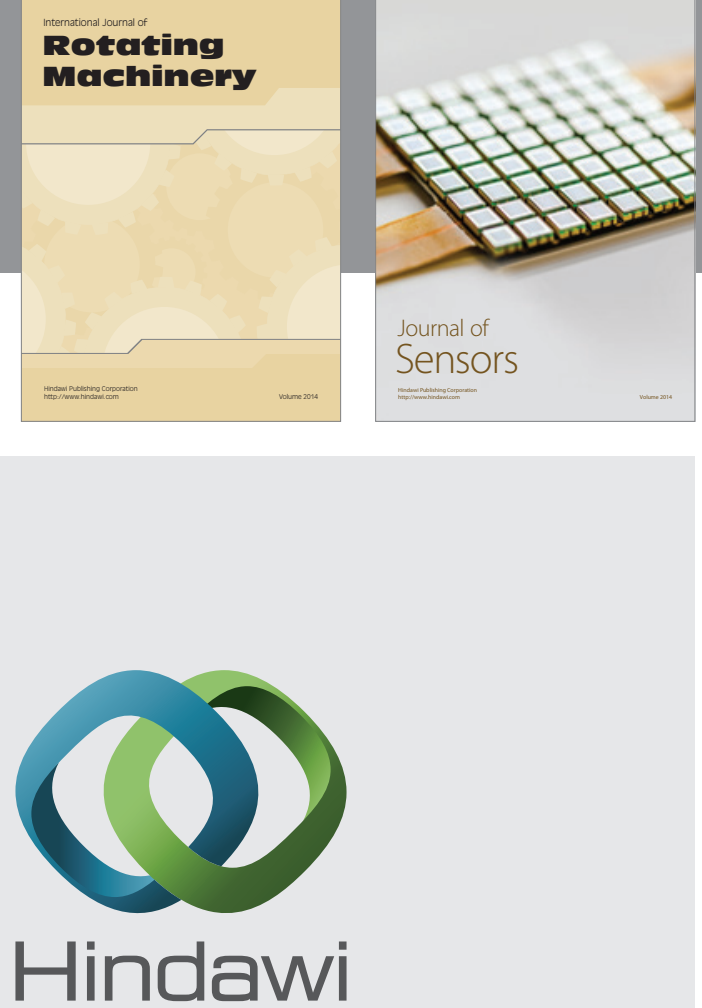

Submit your manuscripts at http://www.hindawi.com
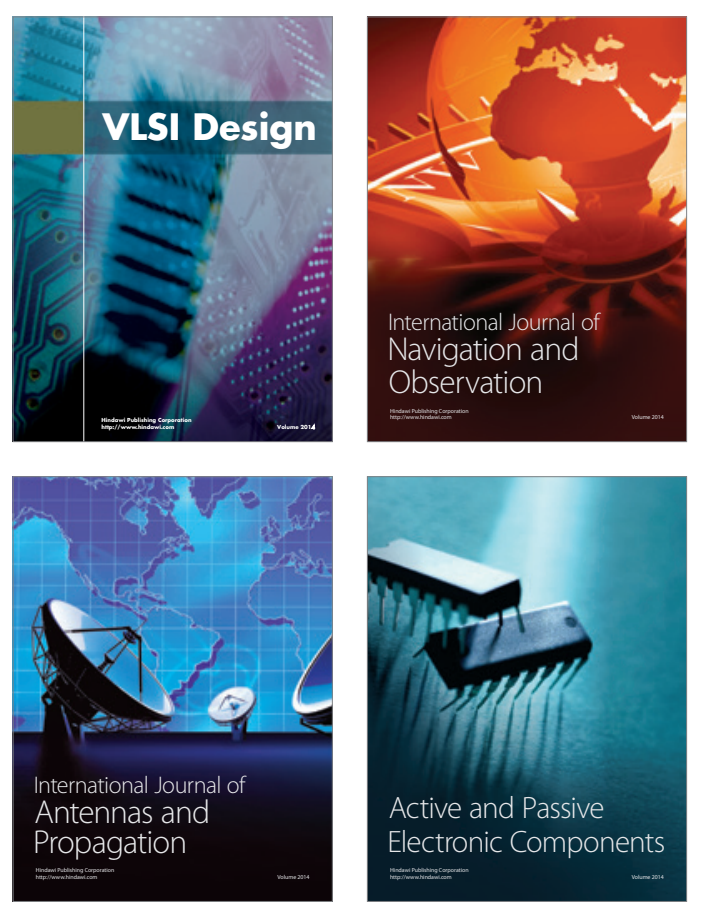
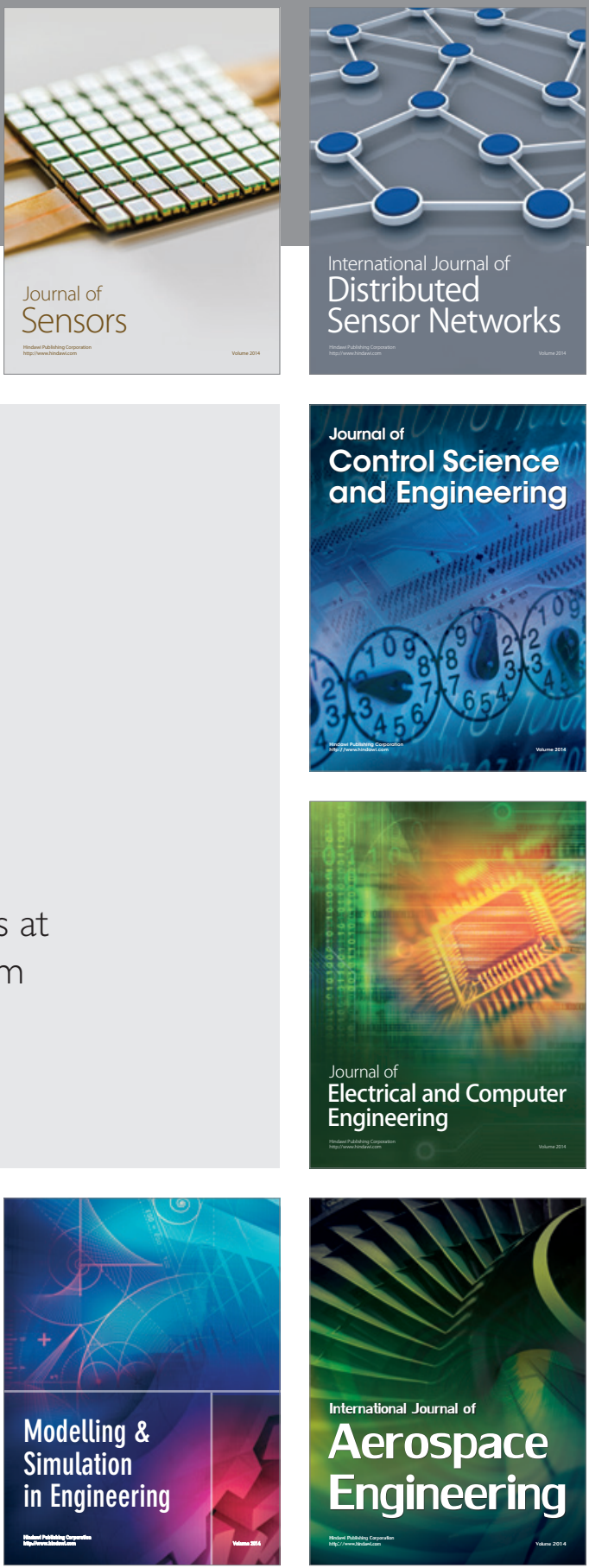

Journal of

Control Science

and Engineering
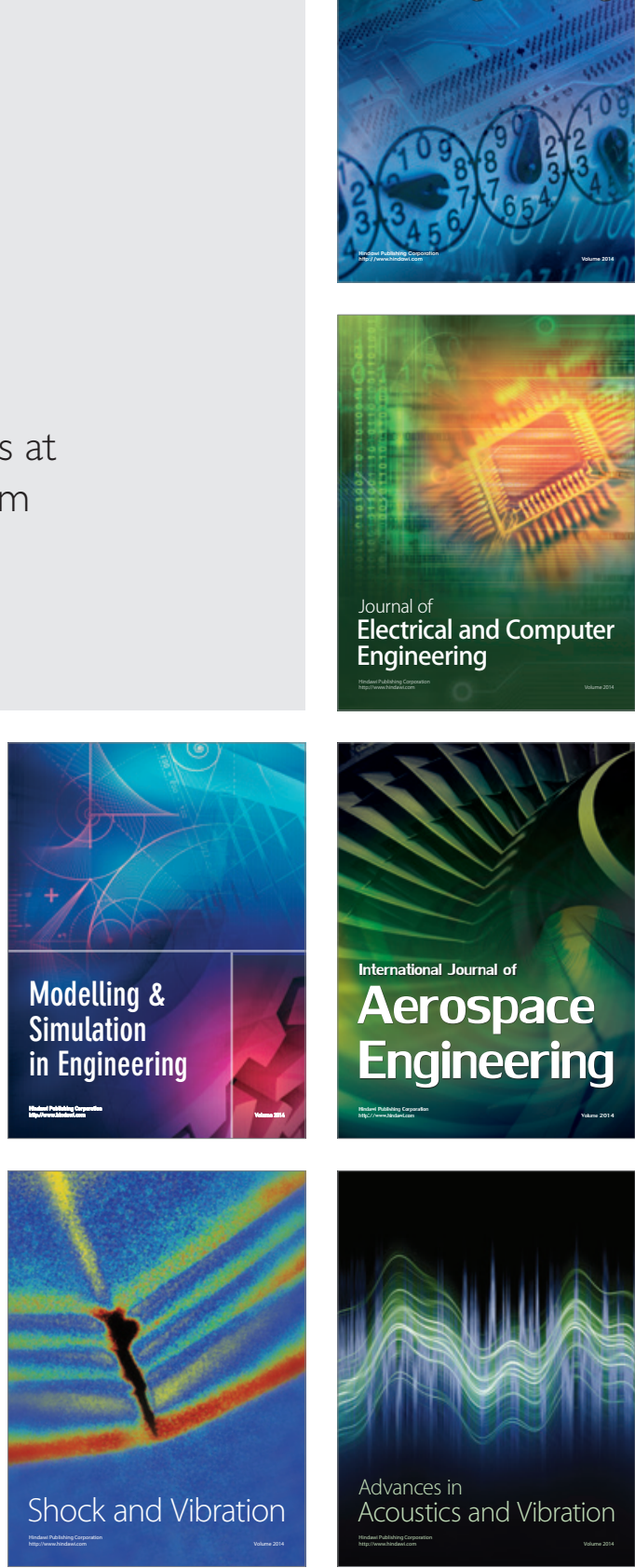